\title{
SUPRAGLOTTIC DEVICES — FUTURE OR EVERYDAY LIFE?
}

\author{
Maciej Sip ${ }^{1,2}$, Agata Dabrowska ${ }^{1,2}$, Karina Prucnal ${ }^{3}$, Mateusz Puslecki ${ }^{1,4}$, Tomasz Klosiewicz ${ }^{1,2}$ \\ ${ }^{1}$ Department of Rescue and Disaster Medicine, Poznan University of Medical Sciences, Poznan, Poland \\ ${ }^{2}$ Polish Society of Medical Simulation, Poland \\ ${ }^{3}$ Journal Club, Poznan University of Medical Sciences, Poznan, Poland \\ ${ }^{4}$ Department of Cardiac Surgery and Transplantology, Poznan University of Medical Sciences, Poznan, Poland
}

\begin{abstract}
The most common cause of upper respiratory tract obstruction in an unconscious or unresponsive patient is the loss of muscle tone in the upper airway. Consequently, this leads to a reduction in the tone of the epiglottis, collapse of the tongue and closure of the airway at the level of the pharynx, preventing respiration. Diagnosing airway obstruction is associated with the implementation of urgent procedures aimed at restoring and maintaining patency. Among the techniques of restoring airway patency anatomically, we prefer extending the head and pushing the posterior mandible forward. Airway ventilation is not always possible through the use of non-surgical methods. Ventilating patients with obstructed airways using a self-inflating bag can prove to be very difficult. In such situations, it is necessary to use airway adjuncts. The purpose, regardless of the circumstances, is to remove anatomical barriers, prevent gastric aspiration and to facilitate proper lung ventilation. Endotracheal intubation is the gold standard for instrumentally maintaining a secure airway. The procedure, however, is reserved for experienced personnel because of how difficult it is to perform and the many complications that arise with it. In situations where difficulty is encountered, an alternative device to secure airway patency is needed.
\end{abstract}

KEY WORDS: endotracheal intubation, alternative airway devices, SAD, supraglottic devices, LMA, LTD, I-gel

Disaster Emerg Med J 2017; 2(2): 74-83

\section{INTRODUCTION}

The most common cause of upper respiratory tract obstruction in an unconscious or unresponsive patient is the loss of muscle tone in the upper airway. Consequently, this leads to a reduction in the tone of the epiglottis, collapse of the tongue and closure of the airway at the level of the pharynx, preventing respiration [1]. An assessment of respiratory and airway compliance, as recommended by the European Resuscitation Council (ERC), should be made by observing the chest while listening to breath sounds and feeling breaths on your cheek or, as recommended by the American Heart Association (AHA), by observing chest rises for $5-10$ seconds $[2,3]$. The patent airway allows outside air to flow into the al- veoli, allowing the oxygenation of the body during the inspiratory phase and eliminates $\mathrm{CO} 2$ during expiration. This process occurs spontaneously in patients with injured airways, or with the help of a rescuer in assisted ventilation [4]. Diagnosing airway obstruction is associated with the implementation of urgent procedures aimed at restoring and maintaining patency. Among the techniques of restoring airway patency anatomically, we prefer extending the head and pushing the posterior mandible forward (the Esmarch maneuver) [3]. Airway ventilation is not always possible through the use of non-surgical methods. Ventilating patients with obstructed airways using a self-inflating bag can prove to be very difficult. In such situations, it is necessary to 
use airway adjuncts. The purpose, regardless of the circumstances, is to remove anatomical barriers, prevent gastric aspiration and to facilitate proper lung ventilation [5]. These apparatuses are recommended in unconscious patients and in those with weakened or absent laryngeal reflexes. For safety reasons and to confirm the patient's state of consciousness, pain response can be assessed using the SqueezeTest. The rescuers use their hands to compress and release the patient's quadriceps muscle, assessing their reaction:

A

- Patient makes a sound (articulates single words) or moans;

- Patient tries to shake the rescuer's hand (shake symptom);

- Patient "runs away with their shoulder" upon encountering the stimulus;

- Patient grimaces in response to pain;

- Patient is mildly unconscious (Grade I).

B

- Patient tries to shake the rescuer's hand (shake symptom);

- Patient "runs away with their shoulder" upon encountering the stimulus;

- Patient grimaces in response to pain;

- Patient is moderately unconscious (Grade II).

$\mathrm{C}$

- Patient "runs away with their shoulder" upon encountering the stimulus;

- Patient grimaces in response to pain;

- Patient is moderate to deeply unconscious (Grade III).

D

- Patient grimaces in response to pain;

- Patient is deeply unconscious (Grade IV).

E

- No pain response;

- Extremely unconscious (Grade V) [4].

If simple manoeuvres are ineffective at maintaining airway patency, consideration should be given to the use of adjuncts. The choice of equipment depends on the patient's condition and the rescuer's capability. Instrumental maintenance of the airways uses an endotracheal tube and a variety of blind devices (BIAD, Blind Insertion Airway Devices) [6].

Endotracheal intubation is considered to be the final method of maintaining airway patency. Intubation allows optimal pressure control during ventilation, prevents stomach distension, prevents gastric aspiration, and allows ventilation to continue during chest compressions during CPR [7]. This procedure is considered the "gold standard" in the management of patients requiring airway restoration and artificial ventilation. Performing tracheal intubation is not a simple procedure. There are several physical features that can predict potential difficulties with intubation. This is demonstrated by the MWOP acronym, namely:

Visualize the throat, tongue without an open oral cavity:

I - Tonsils or residual area visible;

II - Upper pole of the tonsils and their lodging visible;

III - Hard and soft palate visible;

IV - Hard palate visible.

W - dimensions 3-3-1, the ideal distances are:

3 - Ability to place 3 fingers under the patient's chin, between the hyoid bone and the middle of the mandible.

3 - The patient should open their mouth wide enough to allow 3 fingers to be placed between the incisors and mandibular jaw.

1 - The patient should push the jaw forward so that the lower teeth are 1 finger in front of the incisors.

$\mathrm{O}$ - Extension at the atlanto-occipital joint: extending the head to the sniffing position in victims without suspected cervical trauma significantly facilitates the visualization of the larynx.

P - Pathology: any signs of airway obstruction resulting from illness or injury (swelling, infection, burns, penetration or blunt trauma). Intubation-induced stridor is a contraindication for rapid induction [6].

Difficulties include the presence of a cervical-spine stabilizing orthopaedic collar, as this prevents the head-to-back tilt. An additional person is required to assist with the intubation.

Research by Katzenell et al. confirms that intubation is a very challenging operation. The authors assessed the validity of intubation in pre-hospital care based on data from the Israel Defense Forces Trauma Registry. The study group was comprised of 406 individuals, 317 (78\%) of which had a successful intubation performed, irrespective of the number of intubation attempts. Intubation was effective $45 \%, 36 \%$, and $31 \%$ of the time for first, second and third approaches respectively, giving an average of $28 \%$ for all trials [7]. The low effectiveness of successful intubations is usually due to the first responders' inexperience [8]. This is evi- 
denced by a large number of complications such as the displacement of intubation tubes and the lack of confirmed intubation placement by first-responders in $6-17 \%$ of patients $[9,10]$. In addition, increased intubation attempts in patients with sudden cardiac arrest prolong the period without chest compressions in the pre-hospital setting, impairing coronary and cerebral blood flow. Research focusing on pre-hospital intubations trained rescuers during 100 cardiac arrests. In the study on intubation in pre-hospital operations, rescuers were trained with medical training during 100 cardiac arrests. The total duration of CPR interruptions resulting from intubation testing was 110 seconds, and in $25 \%$ was even over 3 minutes [11]. Endotracheal intubation also carries the risk of injury to the tongue, teeth, lips, mucous membranes, vocal folds, or trachea. It can cause vagal nerve stimulation, or inflammation of the epiglottis. Despite its advantages, it is a procedure with many complications and should therefore be performed by trained medical personnel. Persons lacking the necessary skills and experience should use alternative methods of unblocking the airway, such as by using supraglottic devices. They are much easier to use and have a lower risk of complications than endotracheal intubation and, in most cases, they can be introduced without having to interrupt chest compressions.

This work reviews the literature in the context of alternative equipment for endotracheal intubation, which serves to clear the airway. The purpose of the supraglottic device analysis SAD (Supraglottic Airway Device) is to compare the devices in terms of their speed, effectiveness, risk of gastric ventilation and subsequent aspiration, and to assess the potential for traumatic complications.

\section{LMA (LARYNGEAL MASK AIRWAY)}

The LMA device was constructed and patented in 1982 by Dr. Archie lan Jeremy Brain. It was designed to increase the safety, ease and reliability of ventilation. The mask was introduced in the United Kingdom in 1988, followed by the USA in 1992. The LMA serves patients who are deeply unconscious and whose laryngeal reflexes are absent. The LMA combines a flexible tubing with an inflatable cuff resembling an ellipse or pontoon [4]. After inserting the laryngeal mask and using the valve to inflate it with air, the cuff is filled with air, thereby adjusting itself to the shape of the larynx. Properly positioned, the LMA cuff seals off access to the larynx along with neighbouring anatomical structures. The bottom end of the cuff is located in the area of the upper esophageal sphincter, while the top is in contact with the base of the tongue. This position allows the cuff to isolate the remaining anatomical structures (larynx, oropharyngeal cavity and esophagus) while the air is directed to the trachea. The size of the laryngeal mask device depends on the patient's body weight. Prior to LMA insertion, any residual air in the cuff must be absorbed and the distal part of the mask must be lubricated. Once the mask is inserted, the correct placement must be confirmed by auscultating the abdomen and chest, observing for chest rises and by using a $\mathrm{CO}_{2}$ sensor. Once proper insertion is confirmed, the LMA should be stabilized using bandages or adhesives (Fig. $1 \mathrm{a}, \mathrm{b}$ ).

Indications for LMA:

- Ventilation in the event of preserved spontaneous breaths or replacement breaths with a peak pressure $<20 \mathrm{~cm} \mathrm{H}_{2} \mathrm{O}$;

- Limited ability to manoeuvre the patient's head and neck (trauma).

Contraindications:

— Timing of the patient's last meal is too recent (risk of regurgitation) or if there is a lack of information regarding the patient's last meal;

- Aspiration risk exists;

- Relative contraindications include high respiratory pressure or low lung compliance (pulmonary oedema, bronchospasm, respiratory distress, anaphylactic shock, COPD);

- Patients with severe laryngeal injuries and pathological changes in the pharynx.

It is not recommended to perform asynchronous ventilations and compressions during cardiopulmonary resuscitation with the LMA mask. The ventilations should be synchronized with the chest compressions, thus stopping chest compressions to ventilate while avoiding ventilatation patients in PEEP mode [12].

LMA ventilation is not only easier than the bag valve mask method, but also reduces the risk of regurgitation during cardiac arrest [13]. It is much easier to insert the LMA "blindly" than it is with tracheal intubation [14]. LMA does not pose any difficulties during insertion. Studies have shown that the laryngeal mask airway device can be inserted in less than 30 seconds and that it protects the airways in 98-99\% of cases [15]. Taking various conditions into consideration, proper LMA insertion in the in-hos- 


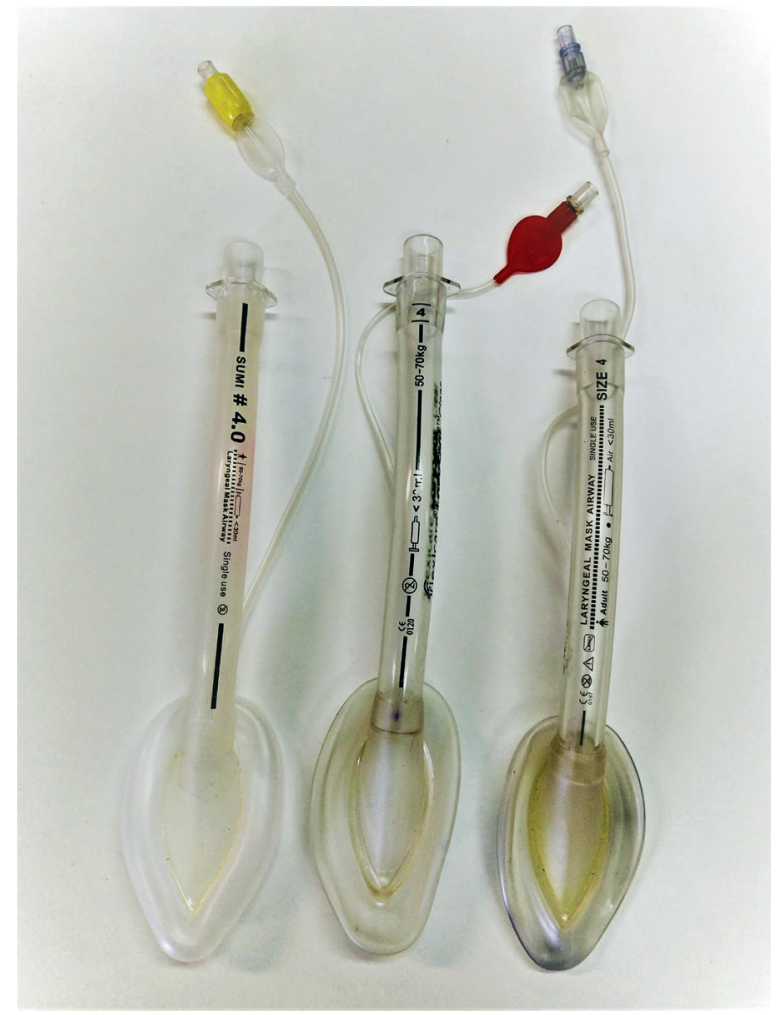

FIGURE 1A. Laryngeal Mask Airway — different LMA

pital setting was 86-100\%, and $71-90 \%$ in the pre-hospital setting (Tab. 1) [16].

\section{LMA-S (LARYNGEAL MASK AIRWAY SUPREME)}

The LMA Supreme Laryngeal Mask is an innovative second-generation device for supraglottic ventilation. It is shaped anatomically like the airway with an elliptical cross section and an inflatable cuff.

The air-filled cuff adjusts to the anatomical structure of the throat, facing the entrance to the larynx. The LMA-S design differs from the LMA in that it has additional tubing that runs along the posterior side of the tube and passes through the distal end of the cuff. It is a decompressive device that ends in contact with the upper esophageal

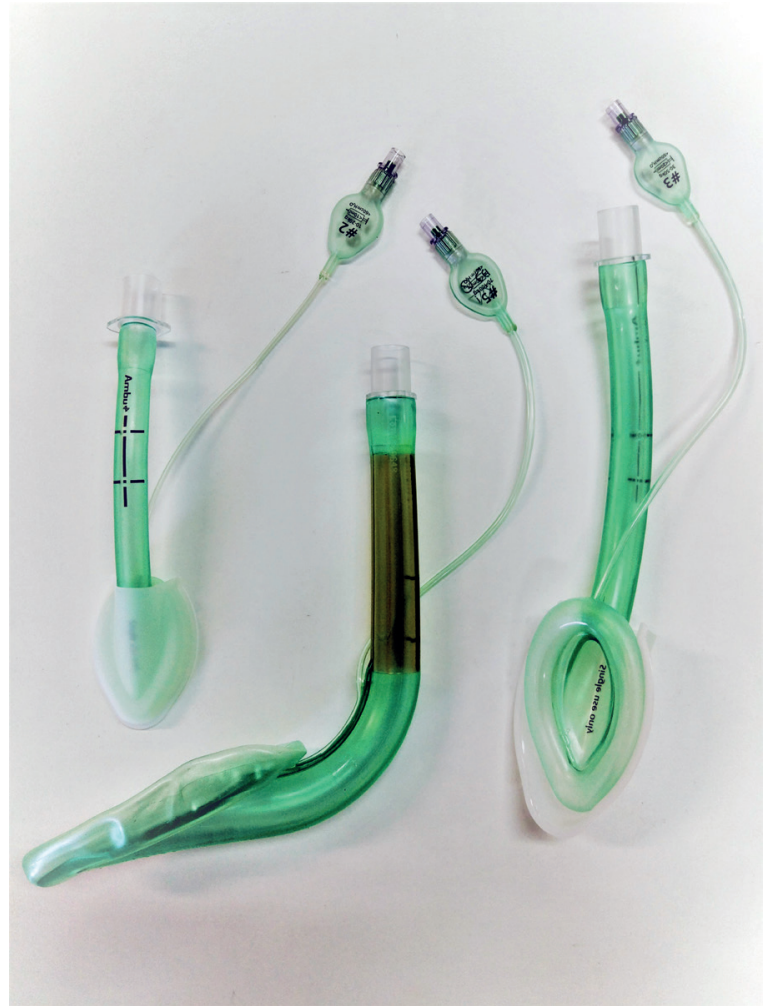

FIGURE 1B. Laryngeal Mask Airway

sphincter. The decompressive drain begins in a separate port, which can evacuate any excess air that has accumulated in the area of the upper esophageal sphincter. In addition, inserting the gastric tube into the stomach allows the contents to be eliminated. This also monitors the correct insertion of the mask and its potential displacement. The presence of two drains and the ability to separate the digestive tract from the airways reduces the risk of aspiration, while maintaining LMA-S air tightness at higher airway pressure values of up to $37 \mathrm{~cm} \mathrm{H} \mathrm{H}_{2} \mathrm{O}$ (Fig. 2) [17, 18].

Indications for LMA-S use:

- Expected or unexpected difficulties maintaining airway patency, in deeply unconscious patients with pharyngeal and laryngeal reflexes intact;

- To maintain airway patency during CPR;

\begin{tabular}{|} 
Table 1. LMA mask sizes \\
\begin{tabular}{|c|c|c|c|}
\hline Size & Patient & Body weight $[\mathrm{kg}]$ & Sealing cuff volume [ml] \\
\hline 1 & Infant & $<6.5$ & $2-5$ \\
\hline 2 & Child & $6.5-20$ & $7-10$ \\
\hline 2.5 & Child & $20-30$ & 14 \\
\hline 3 & Child/Adult & $30-70$ & $15-20$ \\
\hline 4 & Adult & $70-90$ & $25-30$ \\
\hline 5 & Adult & $>90$ & $30-40$ \\
\hline
\end{tabular}
\end{tabular}




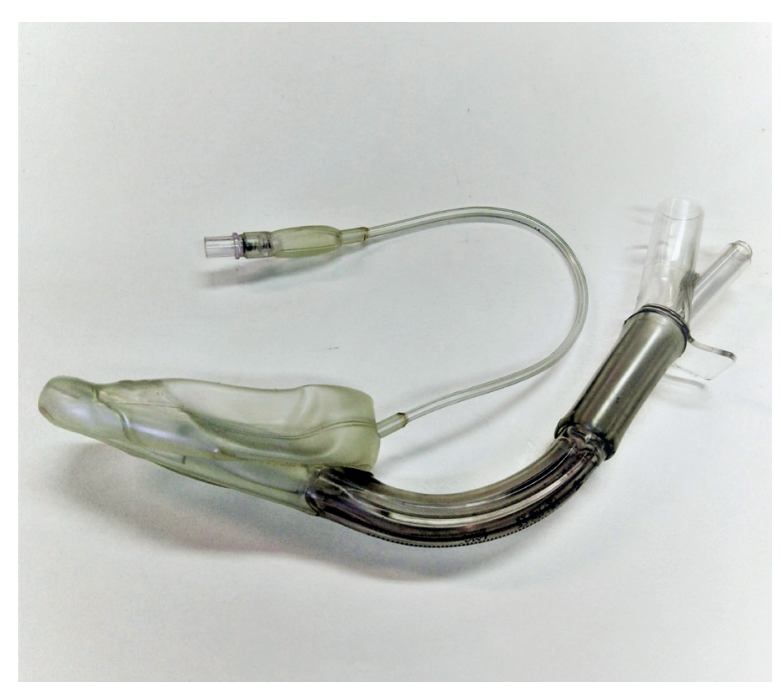

FIGURE 2. Laryngeal Mask Airway Supreme

- Patients at risk for aspiration: more than 14 weeks pregnant, opioid treatment (delayed gastric emptying), massive traumas.

Contraindications:

- Malignant lesions in the pharynx/larynx (risk of ineffective sealing);

- Insufficient opening of the mouth to introduce LMA-S;

- Aggravated airway after the consumption of corrosive substances.

LMA-S is inserted "blindly". It elastic structure prevents any displacement during movements of the patient's head. The two lateral grooves provide additional security against the collapse of the respiratory tract. The size of the laryngeal mask device depends on the patient's body weight (Tab. 2).

\section{I-GEL}

The I-GEL mask is an innovative supraglottic device that has been in use since 2007. Currently, it is frequently used by anaesthesiologists and first-responders. The mask is composed of a wide shaft with an inner narrow conduit. Similar to the LMA-S, it is designed to expel any air that accumulated near the upper esophageal sphincter. Once the gastric tube is inserted into the stomach, it can remove any gastric contents. The material from which it is made is what distinguishes the I-GEL mask from other SAD devices. The cuff of the mask is made from a thermoplastic gel. As a result, the sealing cuff cannot be filled with air. The temperature surrounding the oropharyngeal cavity enables the thermoplastic gel to change its consistency, thus adapting itself to the surrounding anatomical structures. The I-GEL mask protects the respiratory tract well enough to achieve a tightening pressure of $20-40 \mathrm{~cm} \mathrm{H}_{2} \mathrm{O}$ in the larynx [19]. The mask shaft has additional builtin protections to block bites. The size of the I-GEL mask depends on the approximate body weight of the patient.

I-GEL insertion is not difficult, even for inexperienced persons, as demonstrated by studies using I-GEL in mannequins and unconscious patients. Studies assessing I-GEL use in mannequins and unconscious patients showed a high efficiency of $82.5 \%$, with a mean insertion time of 15 seconds (Tab. 3, Fig. 3) [20, 21].

\section{LT-D (LARYNGEAL TUBE DISPOSABLE)}

The disposable LT-D tube was produced in 2001. This is another supraglottic instrument used to ventilate the airway that does not require direct vision for insertion. It is used when endotracheal intubation is not required or as an alternative to other $S A D$ devices. The LT-D tube is constructed from a curved tube with two sealing cuffs. The large oropharyngeal cuff extends from the root of the tongue to

Table 3. I-GEL mask sizes
\begin{tabular}{|c|c|c|}
\hline Size & Patient & Body weight $[\mathrm{kg}]$ \\
\hline 1 & Neonate & $2-5$ \\
\hline 1.5 & Infant & $5-12$ \\
\hline 2 & Child & $10-25$ \\
\hline 2.5 & Large Child & $25-35$ \\
\hline 3 & Young Adult & $30-60$ \\
\hline 4 & Adult & $50-90$ \\
\hline 5 & Large Adult & $90+$ \\
\hline
\end{tabular}

\section{Table 2. LMA-S mask sizes}

\begin{tabular}{|c|c|c|c|}
\hline Size & Patient & Body weight $[\mathrm{kg}]$ & $\begin{array}{c}\text { Sealing cuff } \\
\text { volume }[\mathrm{ml}]\end{array}$ \\
\hline 1 & Infant & $<5$ & 5 \\
\hline 1.5 & Child & $5-10$ & 8 \\
\hline 2 & Child & $10-20$ & 12 \\
\hline 2.5 & Child & $20-30$ & 20 \\
\hline 3 & Child/Adult & $30-50$ & 30 \\
\hline 4 & Adult & $50-70$ & 45 \\
\hline 5 & Adult & $70-100$ & 45 \\
\hline
\end{tabular}




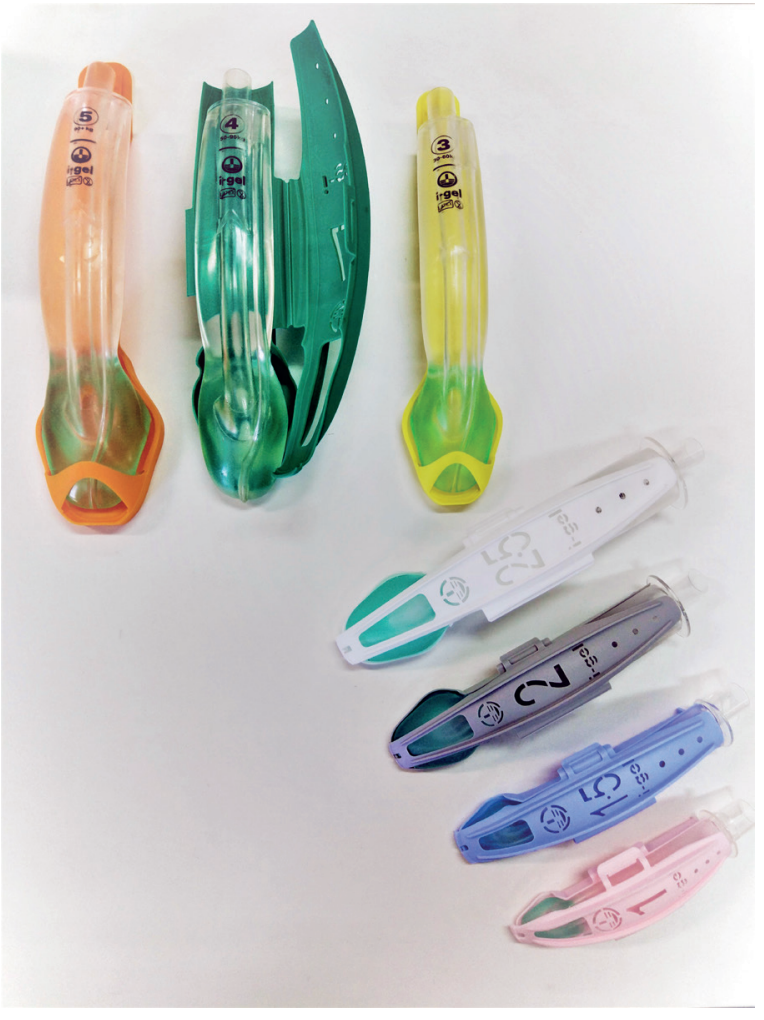

FIGURE 3. I-GEL mask sizes

the soft palate, while the small cuff seals off the esophagus. The cuffs are filled one at a time, each with their own designated syringe. One side of the syringe has a numerical scale demonstrating the volume of air being injected. The opposite side labels various colours. The colours correspond to the size of the LT tubes, which are appropriately labelled at each end. The tube is stabilized once the cuffs are filled. The lower cuff is located in the upper esophageal region, preventing gastric ventilation. Ventilation takes place at the level of the larynx through the air flow that occurs between the oropharyngeal and esophageal cuff. The size of the tube is determined by the patient's height and weight (small sizes). Before insertion, one should check for leaks and then lubricate the tube with gel to facilitate the insertion.

Indications for LT-D use include patients with suppressed reflexes. Contraindications include airway obstruction due to anaphylaxis, inhalation poisoning, or the presence of a foreign body. The device protects the respiratory tract, allowing it to maintain a seal at pressures up to $30 \mathrm{~cm} \mathrm{H}_{2} \mathrm{O}$. The LT-D is known as a simple and effective breathing device. A study focusing on 30 nurses demonstrated effective ventilation in $80 \%$ of the patients with out-of-hospital sudden cardiac arrest. The nurses completed LT-D training in 2 hours [20, 22]. Further research by medical first-responders elucidated that out of the 92 out-of-hospital sudden cardiac arrest patients who received the LT-D tube, 85 were inserted during the first attempt and 7 in the second (Tab. 4, Fig. 4) [23].

\section{COMBITUBE}

This is the oldest device to maintain airway ventilation. The combitube consists of a single tube with a light at each luminal end (esophageal and tracheal). The left (white) light has an opening at the end of the tube, while the right (blue) light ends blindly. This blind end has four pairs of openings. The tube also has two cuffs, namely: white (distal) for the esophageal/tracheal end and blue (proximal) for the pharyngeal.

The cuffs are designed to prevent air from entering the esophagus and returning to the oropharyngeal cavity. The advantage of the Combitube is that, regardless of where it is inserted (esophagus, trachea), it can contribute to effective ventilation. When the tube is inserted into the esophagus, ventilation occurs through the openings. One may use

Table 4. LT-D tube size
\begin{tabular}{|c|c|c|c|}
\hline Size & Patient & Body height/weight & Colour \\
\hline 2 & Child & $90-115 \mathrm{~cm}, 12-25 \mathrm{~kg}$ & Green \\
\hline 2.5 & Child & $120-150 \mathrm{~cm}, 25-35 \mathrm{~kg}$ & Orange \\
\hline 3 & Adult & $<155$ & Yellow \\
\hline 4 & Adult & $155-180 \mathrm{~cm}$ & Red \\
\hline 5 & Adult & $<180 \mathrm{~cm}$ & Violet \\
\hline
\end{tabular}

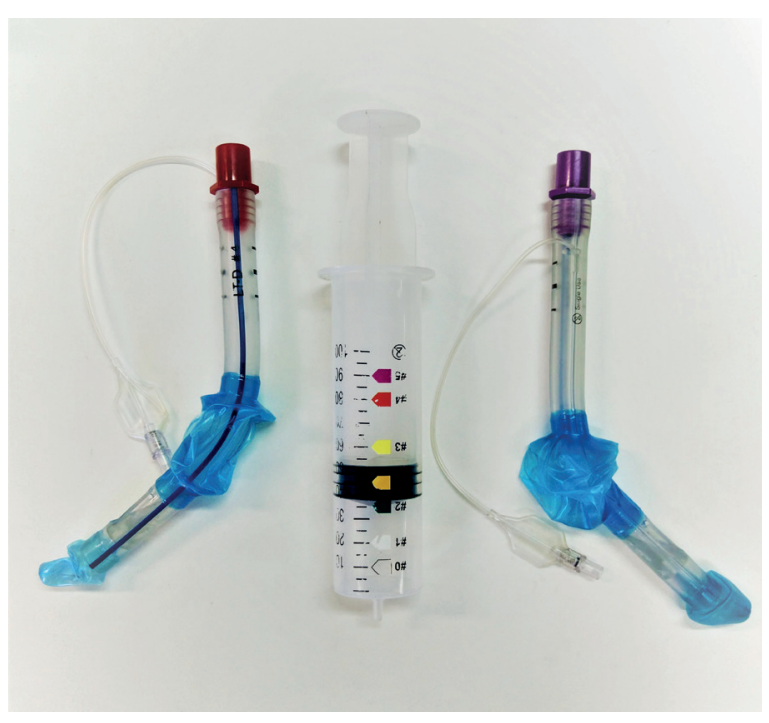

FIGURE 4. LT-D tube sizes with syringe 
the motto "no matter where you insert it - it will be good" [4]. The tube comes in two sizes: for patients with a height between 120-180 cm and for patients with a height of $180 \mathrm{~cm}$ or over. Contraindications include lower pharyngeal and laryngeal injuries [24]. $95 \%$ of the time, the Combitube is inserted into the esophagus. 3.5\% of cases report improper luminal use, leading to gastric distension, regurgitation and subsequent sedation. However, the efficacy of its use during CPR has been confirmed in $79-98 \%$ of patients (Fig. 5).

\section{DISCUSSION}

The results were obtained by comparing the speeds of insertion of selected supraglottic devices, which were obtained from various studies. In a study by Calkins et al., the average time to insert a Combitube vs. LMA by a Navy Seal in a simulated tactical environment was $40.0 \mathrm{~s}$ to $22.3 \mathrm{~s}$ [25]. In a study by Polat et al., which was conducted on 120 patients, the time taken to insert an LMA and I-GEL by one anaesthesiologist was compared and gave a result of $13.1 \mathrm{~s} \pm 1.8 \mathrm{~s}$ vs. $11.6 \mathrm{~s}+2.4 \mathrm{~s}$ [26]. A similar comparison, this time LMA vs I-GEL was performed by Arı et al. on 50 patients, giving a result of $21.00 s \pm 4.15 s$ vs. $30.40 s \pm 12.17 s$ respectively.

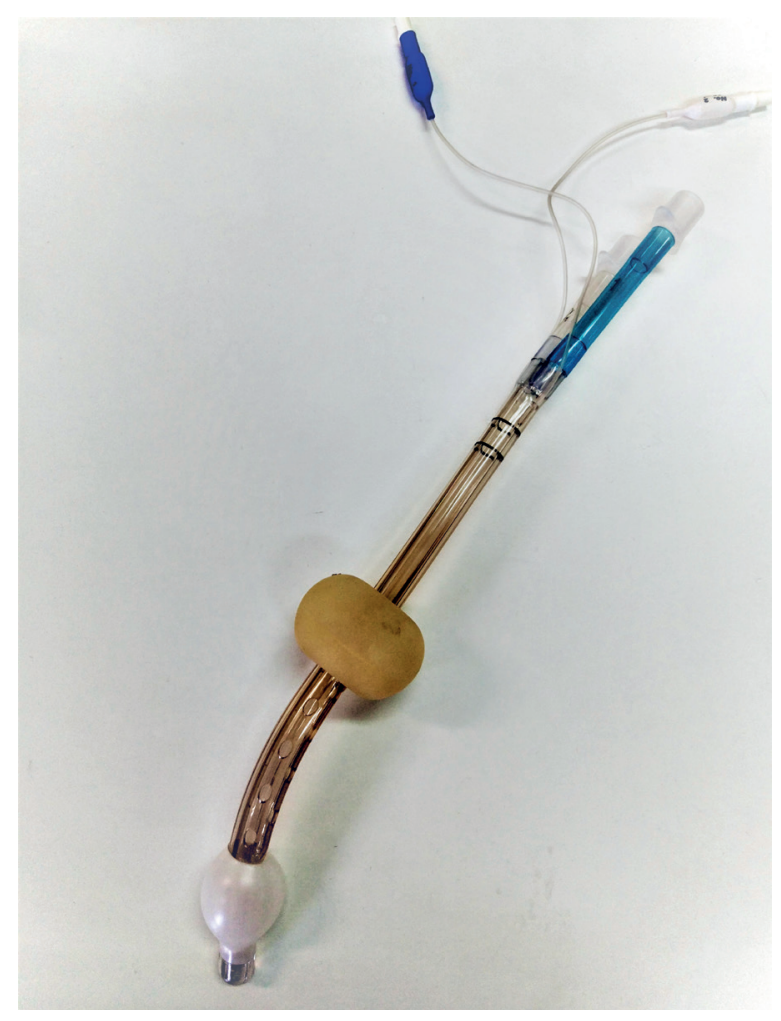

FIGURE 5. Combitube airway device
Länkimäki et al., performed a study on 40 lifeguards without any experience securing airways and evaluated the average time to introduce an LMA Supreme to be $9.8 \mathrm{~s}$ [27]. A study on a group of 50 healthcare specialists who were also inexperienced in airway securing manoeuvres was performed by Chloros et al., and yielded a result of $10.4 \mathrm{~s} \pm 2.7 \mathrm{~s}$ for the insertion of a LMA-S and $13.4 \mathrm{~s} \pm 3.2 \mathrm{~s}$ for the insertion of an LMA [28]. A comparison of insertion times of LMA and LT-D was performed by Ratajczyk et al., and concluded to be $21.94 \mathrm{~s}$ and $51.24 \mathrm{~s}$ [29]. An et al. performed a literature search of studies published up to 2015 through PubMed, EMBASE and Cochrane Library related to SAD devices. The results of this search confirmed that significantly less time was required to administer I-Gel when compared to LMA and Combitube, and there was no difference in the time of application when compared to LMA-S [30]. Detection of visible chest rises during BagValve-Mask ventilation was used as a determinant of effective application of a SAD device. Studies by Polat et al. and Arı et al. both compared evaluations of the effective application of LMA and I-GEL, and neither found a significant difference in efficiency of inserting the devices into airways $[26,31]$. Comparing these same devices in a group of lay people, a study by Kuwahara et al. yielded contrary results, with a significant advantage towards I-GEL [32]. A comparison of LMA and LMA-S in a study by Chloros et al. concluded that healthcare specialists without experience in securing airways will achieve similar results with each device on their first attempt, but favouring LMA-S as their preferred device [28]. In another study, persons without experience in I-GEL effectively introduced it into an airway with an $82.5 \%$ success rate $[10,21]$. Jänig et al. [33] evaluated the effectiveness of administration of LT-D by a group of nurses to be $100 \%$ and $96.3 \%$ when administering LMA. Länkimäki et al. [27] also observed a 100\% effectiveness rating in administering LMA-S by a group of 40 lifeguards. In the case of LMA, a high effectiveness (86-100\%) was observed in in-hospital studies, with a lower result being observed in studies carried out outside of hospitals (71-90\%) [16]. In a study by Kette F. et al., effective insertion of an LT-D was performed with a $92 \%$ success rate [34], as compared to a Combitube tube, which had a success rate of 79-98\% [35].

Opening an airway using a supraglottic device carries the risk of ventilating the stomach and aspirating gastric contents. In a study by Piegeler et al., 
which was performed on cadavers, the risk of aspiration of food contents into the airway was present for 2 in 5 patients when using LMA and I-GEL and 1 in 5 patients when using LT-D [36]. In a study by Pietrzyk et al., it was concluded that the seal of an LT-D device is not tight enough to withstand the pressure in the stomach during the time shortly after eating $\left(30 \mathrm{~cm} \mathrm{H} \mathrm{H}_{2} \mathrm{O}\right.$ ), and that there were not many mentions of choking hazards in the literature referencing the use of LT-D devices. This same team evaluated LMA-S as one of the best SAD devices with respect to aspiration risks. The risk of lowering the esophageal sphincter pressure while inserting the LMA and performing silent aspirations was shown to be $0-80 \%$ [37]. When using a Combitube, approximately $3.5 \%$ of incidents described abdominal distension, regurgitation or choking due to accidental ventilation of the wrong canal.

The introduction of SAD devices may cause the risk of injury, bleeding or directly affect hemodynamic reactions of the body. Arı et al. reported no significant difference in the amount of blood on LMA and I-GEL after removal from the airway [31], while Polat et al., did not report a significant difference in the responses to patients regarding pain after $24 \mathrm{~h}$ of use of the equipment [26]. In a study by Jarineshin et al. there were no significant differences in hemodynamic variables (such as pulse or systolic and diastolic pressures) when comparing LMA and LMA-S devices with endotracheal intubation [38]. Utilization of LMA-S was reported by Van Esch and Kömür et al. to result in the smallest number of airway complications $[39,40]$.

\section{CONCLUSION}

Endotracheal intubation is the gold standard for instrumentally maintaining a secure airway. The procedure, however, is reserved for experienced personnel because of how difficult it is to perform and the many complications that arise with it. In situations where difficulty is encountered, an alternative device to secure airway patency is needed. For comparison, commercially available alternatives were selected, specifically LMA, LMA-S, I-GEL, LT-D and Combitube. Based on several variables, it was concluded that LMA-S ranks the highest in terms of usefulness. The device can be administered very quickly (within approximately $10 \mathrm{~s}$ ) and effectively when compared to other methods, even when used by inexperienced individuals or lay people. SAD devices do not secure airways from food aspiration the way that intubation tubes do. The construction of LMA-S was also found to be superior to $S A D$ devices in preventing aspiration of food particles during vomiting due to its double seal [41]. Introduction of LMA-S is tied to the lowest number of complications (pain, bleeding) and can be safely used even in patients with a suspected cervical spine injury. In evaluating the speed of administration, effectiveness and risk of complication, it was determined that the LMA-Supreme had the greatest advantages.

Conflict of interest: None declared.

\section{REFERENCES}

1. Kluj P, Dąbrowski M, Dąbrowska A, et al. Specyfika udzielania pomocy medycznej poszkodowanemu w warunkach bojowych w środowisku taktycznym w oparciu o standard TCCC Część III. Przywrócenie drożności dróg oddechowych i wydolnego oddechu podczas wykonywania zabiegów ratowniczych w środowisku taktycznym w oparciu o standard TCCC. Anestezjologia i Ratownictwo. 2013; 7: 456-469.

2. Soar J, Nolan JP, Böttiger BW, et al. Adult advanced life support section Collaborators. European Resuscitation Council Guidelines for Resuscitation 2015: Section 3. Adult advanced life support. Resuscitation. 2015; 95: 100-147, doi: 10.1016/j.resuscitation.2015.07.016, indexed in Pubmed: 26477701.

3. Deakin CD, Nolan JP, Soar J, et al. European Resuscitation Council Guidelines for Resuscitation 2010 Section 4. Adult advanced life support. Resuscitation. 2010; 81(10): 1305-1352, doi: 10.1016/j. resuscitation.2010.08.017, indexed in Pubmed: 20956049.

4. Guła P, Machała W. Postępowanie przedszpitalne w obrażeniach ciała. Wydawnictwo lekarskie PZWL, Warszawa 2016.

5. Nakayama DK, Gardner MJ, Rowe MI. Emergency endotracheal intubation in pediatric trauma. Ann Surg. 1990; 211(2): 218-223, indexed in Pubmed: 2301999.

6. Campbell JE. International Trauma Life Support. Ratownictwo przedszpitalne w urazach. Medycyna Praktyczna, Kraków 2015.

7. Katzenell U, Lipsky AM, Abramovich A, et al. Prehospital intubation success rates among Israel Defense Forces providers: epidemiologic analysis and effect on doctrine. J Trauma Acute Care Surg. 2013; 75 (2 Suppl 2): S178-S183, doi: 10.1097/TA.0b013e318299d650, indexed in Pubmed: 23883905.

8. Garza AG, Gratton MC, Coontz D, et al. Effect of paramedic experience on orotracheal intubation success rates. J Emerg Med. 2003; 25(3): 251-256, indexed in Pubmed: 14585451.

9. Jones JH, Murphy MP, Dickson RL, et al. Emergency physician-verified out-of-hospital intubation: miss rates by paramedics. Acad Emerg Med. 2004; 11(6): 707-709, indexed in Pubmed: 15175215.

10. Nolan JP, Soar J. Airway techniques and ventilation strategies. Curr Opin Crit Care. 2008; 14(3): 279-286, doi: 10.1097/MCC.0b013e3282f85bc8, indexed in Pubmed: 18467887. 
11. Wang HE, Simeone SJ, Weaver MD, et al. Interruptions in cardiopulmonary resuscitation from paramedic endotracheal intubation. Ann Emerg Med. 2009; 54(5): 645-652.e1, doi: 10.1016/j. annemergmed.2009.05.024, indexed in Pubmed: 19573949.

12. Sierpina DI, Chaudhary H, Walner DL, et al. Laryngeal mask airway versus endotracheal tube in pediatric adenotonsillectomy. Laryngoscope. 2012; 122(2): 429-435, doi: 10.1002/lary.22458, indexed in Pubmed: 22252780.

13. Alexander R, Hodgson P, Lomax D, et al. A comparison of the laryngeal mask airway and Guedel airway, bag and facemask for manual ventilation following formal training. Anaesthesia. 1993; 48(3): 231-234, indexed in Pubmed: 8460803.

14. Deakin $C D$, Peters $R$, Tomlinson $P$, et al. Securing the prehospital airway: a comparison of laryngeal mask insertion and endotracheal intubation by UK paramedics. Emerg Med J. 2005; 22(1): 64-67, doi: 10.1136/emj.2004.017178, indexed in Pubmed: 15611551.

15. Brimacombe J. Laryngeal Mask Anesthesia. Principles and Practice. Saunders Elsevier Ltd, London 2005.

16. Ocker $H$, Wenzel V, Schmucker $P$, et al. A comparison of the laryngeal tube with the laryngeal mask airway during routine surgical procedures. Anesth Analg. 2002; 95(4): 1094-7, table of contents, indexed in Pubmed: 12351302.

17. Cook TM, Gatward JJ, Handel J, et al. Evaluation of the LMA Supreme in 100 non-paralysed patients. Anaesthesia. 2009; 64(5): 555-562, doi: 10.1111/j.1365-2044.2008.05824.x, indexed in Pubmed: 19413827.

18. Zundert AV, Brimacombe J. The LMA SupremeTM- a pilot study. Anaesthesia. 2008; 63(2): 202-213, doi: 10.1111/j.13652044.2007.05421.x.

19. Wharton NM, Gibbison B, Gabbott DA, et al. l-gel insertion by novices in manikins and patients. Anaesthesia. 2008; 63(9): 991-995, doi: 10.1111/j.1365-2044.2008.05542.x, indexed in Pubmed: 18557971.

20. Nolan JP, Soar J, Zidman DA et al. European Resuscitation Council Guidelines for Resuscitation. Section 1. E. 2010.

21. Abukawa Y, Hiroki K, Ozaki M. Initial experience of the i-gel supraglottic airway by the residents in pediatric patients. J Anesth. 2012; 26(3): 357-361, doi: 10.1007/s00540-011-1322-1, indexed in Pubmed: 22310833.

22. Kette F, Reffo I, Giordani G, et al. The use of laryngeal tube by nurses in out-of-hospital emergencies: preliminary experience. Resuscitation. 2005; 66(1): 21-25, doi: 10.1016/j.resuscitation.2004.12.023, indexed in Pubmed: 15993725.

23. Wiese CHR, Semmel T, Müller JU, et al. The use of the laryngeal tube disposable (LT-D) by paramedics during out-of-hospital resuscitation-an observational study concerning ERC guidelines 2005. Resuscitation. 2009; 80(2): 194-198, doi: 10.1016/j.resuscitation.2008.08.023, indexed in Pubmed: 19010582.

24. Mahajan $R$, Charak DS, Bassi $R$, et al. Trachlight-guided intubation with esophageal combitube in situ. J Anaesthesiol Clin Pharmacol. 2012; 28(4): 544-545, doi: 10.4103/0970-9185.101963, indexed in Pubmed: 23225955.
25. Calkins MD, Robinson TD. Combat trauma airway management: endotracheal intubation versus laryngeal mask airway versus combitube use by Navy SEAL and Reconnaissance combat corpsmen. J Trauma. 1999; 46(5): 927-932, indexed in Pubmed: 10338414.

26. Polat R, Aydin GB, Ergil J, et al. Comparison of the i-gel ${ }^{T M}$ and the Laryngeal Mask Airway Classic ${ }^{\mathrm{TM}}$ in terms of clinical performance. Braz J Anesthesiol. 2015; 65(5): 343-348, doi: 10.1016/j. bjane.2014.02.009, indexed in Pubmed: 26323731.

27. Länkimäki S, Alahuhta S, Silfvast T, et al. Feasibility of LMA Supreme for airway management in unconscious patients by ALS paramedics. Scand J Trauma Resusc Emerg Med. 2015; 23: 24, doi: 10.1186/ s13049-015-0105-3, indexed in Pubmed: 25888519.

28. Chloros T, Xanthos T, lacovidou N, et al. Supreme Laryngeal Mask Airway achieves faster insertion times than Classic LMA during chest compressions in manikins. Am J Emerg Med. 2014; 32(2): 156-159, doi: 10.1016/j.ajem.2013.10.048, indexed in Pubmed: 24332907.

29. Ratajczyk P, Małachowska B, Gaszyńska E, et al. A randomised comparison between Cobra PLA and classic laryngeal mask airway and laryngeal tube during mechanical ventilation for general anaesthesia. Anaesthesiol Intensive Ther. 2013; 45(1): 20-24, doi: 10.5603/ AlT.2013.0004, indexed in Pubmed: 23572303.

30. An J, Nam SB, Lee JS, et al. Comparison of the i-gel and other supraglottic airways in adult manikin studies: Systematic review and meta-analysis. Medicine (Baltimore). 2017; 96(1): e5801, doi: 10.1097/MD.0000000000005801, indexed in Pubmed: 28072732.

31. Arı DE, Ar AY, Karip CŞ, et al. Comparison of I-gel with Classic Laryngeal Mask Airway Regarding the Ease of Use and Clinical Performance. Turk J Anaesthesiol Reanim. 2015; 43(5): 299-303, doi: 10.5152/ TJAR.2015.71542, indexed in Pubmed: 27366518.

32. Kuwahara Y, Taguchi S, Kusunoki S, et al. Use of i-gel supraglottic airway for emergency airway management by novice personnel in comparison with laryngeal mask airway and tracheal intubation in manikin models. Masui. 2013; 62(5): 592-595, indexed in Pubmed: 23772535.

33. Jänig C, Wenzel J, König J, et al. Airway management techniques in a restricted-access situation: a manikin study. Eur J Emerg Med. 2016; 23(4): 286-291, doi: 10.1097/MEJ.0000000000000273, indexed in Pubmed: 25933035.

34. Kette F, Reffo I, Giordani G, et al. The use of laryngeal tube by nurses in out-of-hospital emergencies: preliminary experience. Resuscitation. 2005; 66(1): 21-25, doi: 10.1016/j.resuscitation.2004.12.023, indexed in Pubmed: 15993725.

35. Lefrançois DP, Dufour DG. Use of the esophageal tracheal combitube by basic emergency medical technicians. Resuscitation. 2002; 52(1): 77-83, indexed in Pubmed: 11801352.

36. Piegeler T, Roessler B, Goliasch G, et al. Evaluation of six different airway devices regarding regurgitation and pulmonary aspiration during cardio-pulmonary resuscitation (CPR) - A human cadaver pilot study. Resuscitation. 2016; 102: 70-74, doi: 10.1016/j.resuscitation.2016.02.017, indexed in Pubmed: 26921473. 
37. Pietrzyk M, Grześkiewicz M, Gaszyński W, et al. Porównanie urządzeń nadkrtaniowych do udrażniania dróg oddechowych pod względem zabezpieczenia przed zachłyśnięciem treścią żołądkową - badanie manekinowi. Anestezjologia i Ratownictwo. 2011; 5: 436-441.

38. Jarineshin $H$, Kashani S, Vatankhah M, et al. Better Hemodynamic Profile of Laryngeal Mask Airway Insertion Compared to Laryngoscopy and Tracheal Intubation. Iran Red Crescent Med J. 2015; 17(8): e28615, doi: 10.5812/ircmj.28615, indexed in Pubmed: 26430529.

39. van Esch BF, Stegeman I, Smit AL. Comparison of laryngeal mask airway vs tracheal intubation: a systematic review on airway complications. J Clin Anesth. 2017; 36: 142-150, doi: 10.1016/j. jclinane.2016.10.004, indexed in Pubmed: 28183554

40. Kömür E, Bakan N, Tomruk ŞG, et al. Comparison of the Supraglottic Airway Devices Classic, Fastrach and Supreme Laryngeal Mask Airway: A Prospective Randomised Clinical Trial of Efficacy, Safety and Complications. Turk J Anaesthesiol Reanim. 2015; 43(6): 406-411, doi: 10.5152/TJAR.2015.97830, indexed in Pubmed: 27366537.

41. Szarpak $\measuredangle$, Kurowski A, Osłowski $R$, et al. Alternatywne metody udrażniania dróg oddechowych u dzieci. Nowa Pediatria. 2014; 3: 92-96. 